\title{
Disease Response in Spleen
}

National Cancer Institute

\section{Source}

National Cancer Institute. Disease Response in Spleen. NCI Thesaurus. Code C135482.

An assessment of the disease response to therapy within the involved spleen. 